\title{
Die Vernunft in den Zeiten der Schweinegrippe
}

\section{Ines Kappstein}

Für die normale Influenzasaison werden bisher in Deutschland pro 1Mio. Einwohner ca. 100-140 Todesfälle durch Influenza berichtet. Daraus ergeben sich laut RKI ca. 8000 bis 11000 zusätzliche Todesfälle pro Jahr (www.rki.de > RKI-Ratgeber). In Australien, wo derzeit der Winter schon vorbei ist, gab es in dieser Influenzasaison 190 Todesfälle bei Personen, die an der neuen Influenza A/H1N1 erkrankt waren. Eine normale saisonale Influenza, die in Australien alljährlich mit 2000-3000 Todesfällen verbunden ist, hat es dort Medienberichten zufolge im Winter 2009 nicht gegeben (Monitor vom 19. 11.09). In Australien scheint 2009 also die normale saisonale Influenza ausgeblieben und durch die neue Influenza ersetzt worden zu sein. Dies wäre nicht neu, denn 1957 hat der Erreger der damaligen asiatischen Grippe (A/H2N2) das bis dahin zirkulierende A/H1N1, ein Nachfahre des Pandemie-Virus von 1918, ersetzt. In ähnlicher Weise ersetzte 1968 der Erreger der so genannten Hongkong-Grippe (A/H3N2) das seit 1957 aktive Virus [1].

Legt man die Einwohnerzahl Australiens mit 22 Mio. zugrunde, dann war dort das Risiko, an der neuen Influenza zu sterben, mit 0,0009\% oder 9 Fällen pro 1 Mio. Einwohner sehr viel geringer als das Sterblichkeitsrisiko im Zusammenhang mit der üblichen saisonalen Influenza. Diese Zahlenverhältnisse wurden in Deutschland nur unzureichend zur Kenntnis genommen. Statt auf die aktuellen Erfahrungen in Australien zurückzugreifen, wo ein vergleichbar modernes und effektives Gesundheitssystem etabliert ist wie in den Industrieländern der Nordhalbkugel, orientierte man sich hier lieber an Absolutzahlen, die aber lediglich „Emotionen (wecken), für die Beschreibung von Risiken haben sie keine Bedeutung“" (Gerd Antes, Süddeutsche Zeitung vom 7./8. 11. 2009). Denn, so Antes dort, „Nutzen und Risiken werden mit Quotienten beschrieben!“. Damit kann man aber keine Schlagzeilen machen oder hohe Einschaltquoten erzielen. Diese Vorgehensweise betrifft jedoch nicht nur die Medien.

Wegen der großen Unsicherheit über die Auswirkungen der neuen Influenza kamen Fachleute aus dem Gebiet der Infektionskrankheiten in den vergangenen
Monaten vielfach im Fernsehen zu Wort und erläuterten dort ihre Sicht auf die neue Influenza, häufig nicht ohne auf die dramatischen Auswirkungen der sog. spanischen Grippe von 1918 zu verweisen. Diese „Mutter aller Pandemien“ [2] diente vielen Experten (und im Gefolge auch Politikern) dazu, gebetsmühlenartig auf ein mögliches Schreckensszenario hinzuweisen, nämlich die Veränderung des ursprünglichen Influenzavirus A/H1N1/2009 via Antigendrift und/oder -shift hin zu einem tödlichen Virus à la 1918. In der Tat wissen wir immer noch nicht, was sich aus dem heutigen $\mathrm{A} /$ H1N1/2009 entwickeln wird. Dass es sich verändern wird, wenn es weiter unter uns Menschen bleibt, ist gewiss, weil sich so alle Influenzaviren verhalten (haben), die nach einer 1 . Welle weiter zwischen den Menschen zirkulieren und diese infizieren. Vollkommen ungewiss ist dagegen, ob eine Virusvariante entstehen wird, die wieder, wie bereits 1918, in der Lage ist, bei Millionen von Menschen eine zum Tode führende Infektion zu verursachen. Seriöse Voraussagen sind nicht möglich. Man kann lediglich sagen, dass eine solche Entwicklung nicht ausgeschlossen ist, und zwar einfach deshalb, weil es 1918 so geschah [2,3]. Mehr Hinweise gibt es nicht. Allerdings gäbe es über die spanische Grippe von 1918 viel mehr zu sagen, als das, was wir leider auch von Fachleuten in den Medien ständig wiederholt gehört haben [2].

Beispielsweise könnte man - auch zur Beruhigung der Bevölkerung - erwähnen, dass die 1918er Grippe wahrscheinlich auch deshalb so viele Todesopfer (auch und gerade unter Soldaten) forderte, weil die Bevölkerung durch den ersten Weltkrieg in hohem Maße physisch und psychisch belastet war und aufgrund der äußeren Umstände zu wenig Abwehrkräfte mobilisieren konnte. Die Opfer waren damals besonders hoch bei jungen Erwachsenen [2], also der Altersgruppe vieler Soldaten und ihrer Frauen, die zu Hause allein mit den Kindern zurecht kommen mussten. Diese Altersgruppe, so vermutet man, war auf einen für sie neuen Influenzaerreger immunologisch nicht vorbereitet, denn ältere Menschen, die noch die Influenzapandemie von 1889 miterlebt hatten, erkrankten deutlich seltener: Während die über 65-Jährigen in der Zeit 
zwischen 1900 und 1917 einen Anteil von 6\% an allen Influenzafällen hatten, fiel dieser Anteil 1918 auf 0,6\%; ebenso verhielt es sich bei der Sterblichkeit [2]. Völlig ungeklärt ist indes, wie sich das 1918er Virus innerhalb weniger Monate derart verändert haben soll, denn normalerweise „driften“ Influenzaviren wesentlich langsamer, benötigen dazu nämlich gewöhnlich Jahre [2]. Es ist noch nicht einmal klar, ob es sich bei dem Virus der 1. 1918er Welle um dasselbe Virus wie bei der 2. und 3. Welle gehandelt hat, denn man kennt nur das Virus der 2. pandemischen Welle [2].

Außerdem müsste gesagt werden, dass es 1918 weder intensivmedizinische Möglichkeiten mit maschineller Beatmung für die Personen mit schwerer Pneumonie gab (Hauptursache der damaligen Todesfälle waren schwere und komplizierte respiratorische Erkrankungen) noch Antibiotika zur Therapie bakterieller Superinfektionen. Weiterhin wäre es durchaus interessant zu berichten, dass es damals (auch bei anderen Erkrankungen, wie rheumatischem Fieber) Behandlungsmethoden gab, die viele Influenzapatienten zusätzlich zu ihrer erkrankungsbedingten Lungenschädigung einem erheblichen iatrogenen Risiko aussetzten: So wurde nämlich Azetylsalizylsäure in heute als akut toxisch bekannten Tagesdosen $(8-30 \mathrm{~g})$ verabreicht, die z. B. zu einem Lungenödem führen können [4]: Nachdem im September 1918 die offizielle Empfehlung für die Influenzatherapie heraus war, kam es kurz danach zu einem deutlichen Anstieg der Todeszahlen, zunächst bei Angehörigen des Militärs, dann auch in der allgemeinen Bevölkerung [4]. Man wusste es eben damals nicht.

All das wäre heute geeignet gewesen, der Bevölkerung via Medien mitzuteilen. Stattdessen wurde ständig wiederholt, dass die 1918er Grippe auch erst mild begann. Dann wurde die neue Impfung abwechselnd für sicher und für unsicher erklärt. Als sich aber im Herbst abzeichnete, dass der Impfwille in der Bevölkerung nur gering ausgeprägt war, wurden in den Medien einzelne Todesfälle ausgebreitet mit dem Ergebnis, dass sich dann mehr Menschen impfen lassen wollten, als überhaupt Impfstoff verfügbar war. Der aber war zunächst nur für 25-30\% der Bevölkerung bestellt, nämlich für die Risikogruppen (z.B. Beschäftigte im Gesundheitsdienst, Polizei, Personen mit disponierenden Grundkrankheiten), die somit nicht verabreicht bekommen konnten, was an sich für sie vorgesehen war.

Weiter ging es damit, dass Schwangere und Kleinkinder geimpft werden sollten, aber nicht mit einem adjuvantierten Impfstoff. Auf einen nicht adjuvantierten Impfstoff mussten diese Risikogruppen fast bis zum Jahresende warten. Chaotische Information von offizieller Seite, viel Durcheinander in den Medien und vor kurzem auch noch ein Experte, der sagt, dass der hohe Anstieg der Schweinegrippefälle in Bayern mit dem Oktoberfest zusammenhängt: Die starke Zunahme in Bayern begann in der 44. KW, das Oktoberfest fand statt in der 39. und 40. KW. Die Inkubationszeit beträgt maximal 4 Tage. 4 Wochen Latenz nach dem Oktoberfest. Das passt irgendwie nicht zusammen. Insgesamt ein bisschen mehr Vernunft hätte gut getan.

\section{Literatur}

1 Morens DM, Taubenberger JK, Fauci AS. The persistence legacy of the 1918 influenza virus. N Engl J Med 2009; 361: 225-229

2 Taubenberger JK, Morens DM. 1918 influenza: the mother of all pandemics. Em Infect Dis 2006; 12: $15-22$

3 Sepkowitz KA. Forever unprepared: The predictable unpredictablitiy of pathogens. N Engl J Med 2009; 361: $120-121$

4 Starko KM. Salicylates and pandemic influenza mortality, 1918 - 1919 pharmacology, pathology, and historic evidence. Clin Infect Dis 2009; 49: $1405-1410$ 